\title{
EL TRATADO
}

\section{ALTAMIRANO - HARRISON}

ALEJANDRO MONTIEL ARGÜELLO

\section{LA TAGUZGALPA}

$\mathrm{E}$ 1 día 24 de Agosto del año en curso se cumple el primer cincuentenario del canje de ratificaciones del tratado ALTAMIRANO- HARRISON entre Nicaragua e Inglaterra, quedando vencidas en esa fecha las obligaciones asumidas por la primera en compensación sobre la Costa Atlántica.

En los primeros años de la conquista española ésta se redujo sólo ala zona del Pacífico, donde se fundaron las ciudades coloniales que hoy subsisten y donde todavia se encuentra concentrada la gran mayoria de la población y la actividad económica. La costa atlántica. denominada entonces la TEGUZGALPA. permaneció insumisa y era habitada en esa época por los indios JICAQUES, elemento autóctono de los actuales pobladores de ella.

En 1562 la conquista y reducción de la TEGUZGALPA fue confiada al gobernador de Honduras, licenciado Alonso ORTIZ de ELEGUETA, pero nada se hizo para llevarla a la práctica, y pocos años después otro gobernante hondureño. Rodrigo Ponce de León solicita la autorización del rey, informando entusiasmado, con respecto a los habitantes del TAGUZGALPA. que la tierra adentro tienen una casa en una gran población que una laguna de donde dicen que llevaban el oro a México en tiempo de MOTECUMA. 
Habiendo fracasado estos intentos y algunos otros que no creemos necesario referir, se intento hacer la reducción de los indios por medios pacíficos y fue enviado el misionero franciscano Fray Esteban de VERDELETE a catequizarlos en la religión católica.

En los años subsiguientes no se hizo ningún intento formal de reducción y solo ocurrieron pequeñas escaramuzas en la región fronteriza, provocadas por las constantes incursiones que los indios hacian en las regiones habitadas por los españoles.

\section{LA GUERRA DE LOS TRECE AÑOS}

En el año de 1641 naufraga en la costa atlántica un barco cargado de negros esclavos, quienes se mezclaron con los JICAQUES o mosquitos dando lugar al tipo híbrido llamado Zambo. Los ingleses, desde sus su base de Jamaica arrebatada a España en 1656, entablaron relaciones de amistad con los mosquitos y zambos, y en 1687 llevaron a Jamaica a uno de los caciques. OLDMAN, y lo hicieron coronar Rey de los mosquitos.

Esta táctica de los ingleses de atraerse a los mosquitos y zambos produjo resultado al declararse entre España e Inglaterra la guerra llamada de sucesión o de los trece años provocada por el testamento de Carlos II el hechizado, último monarca español de la casa de Austria, fallecido el 19 de noviembre de 1700, quien instituyó como heredero de la corona a Felipe de ANJOU y BORBÓN, después Felipe V, hijo de Luis XIV de Francia y de María Teresa de Austria, hermana ésta del testador.

Los ingleses hicieron causa común con la casa de Austria representada por LEOPOLDO I, para impugnar el testamento, y en prevención de los ataques que ellos pudieran hacer en centro América, por real cédula del 28 de abril de 1703 se ordeno al capitán General de Guatemala que pusiera en estado de defensa las costas y puertos del mar del norte.

A pesar de estas precauciones, en 1704 una banda de ingleses y mosquitos remontó el río coco y asalto la ciudad de Segovia, y otra banda asalto el pueblo de AMATIQUE en el golfo dulce. en 1707 hicieron una entrada a MATINA y en 1708 otra al PETÉN.

\section{LA GUERRA DE 1739}

En los años subsiguientes se hicieron, discutieron y aprobaron planes y más planes para la reducción de los mosquitos y zambos, pero ninguno fue puesto en ejecución, y en 1739 se renovó la guerra entre España e Inglaterra. 
Una poderosa escuadra inglesa, al mando del almirante EDWARD VERNON, se presento frente a Cartagena de indias y aunque logro destruir la flota española en ese puerto y alguno de los fuertes del mismo, tuvo que retirarse a Jamaica sin haber logrado la captura de la plaza que le hubiera servido de base para la conquista de la América Española.

En el año de 1747 fue atacado el pueblo de LÓVAGO y al año siguiente los ingleses se apoderaron por sorpresa del puerto de San Juan del Norte, aunque lo devolvieron a España al firmarse ese mismo año la paz de AIX -LA-CHAPELLE. Este tratado no fue sin embargo el fin de las hostilidades, pues al año siguiente los ingleses y mosquitos tomaron y saquearon las ciudades de CAMOAPA y BOACO en CHONTALES. Poco tiempo después vino un periodo de paz y HODGSON llego a hacer creer a las autoridades españolas que esa paz se debía a sus esfuerzos, por lo cual le fue conferido él titulo de coronel.

Es del caso de interés de los ingleses en los establecimientos de la MOQUITIA no era puramente bélico sino también económico, pues se servian de ellos para la explotación de maderas y sobre todo para el contrabando. y muchas veces contaban para esto ultimo con la complicidad de funcionarios españoles.

\section{RAFAELA HERRERA}

En 1762 se rompieron nuevamente las hostilidades entre Inglaterra y España a consecuencia del llamado pacto de familia entre esta ultima y Francia.

El gobernador de Jamaica intentó invadir Nicaragua por el río San Juan con una armada de cincuenta embarcaciones tripuladas por dos mil hombres. La armada ascendió el río San Juan y llego al frente de la Inmaculada CONSEPCION en momentos en que el comandante de la fortaleza. JOSE o PEDRO HERRERA. se encontraba agonizando. e intimó la rendición.

En esos momentos angustiosos, la hija del castellano, RAFAELA HERRERA, de apenas 19 años de edad, asumió el mando de la fortaleza y se negó a rendirla.

Los ingleses abrieron fuego contra el castillo y RAFAELA disparo los primeros cañonazos y dirigió la defensa, con tan buena suerte que al tercer disparo mato al comandante de la armada enemiga y echó a pique uno de sus buques.

Continuo la lucha ininterrumpidamente, y en la noche del cuarto dia. RAFAELA HERRERA hizo empapar unas sabanas en alcohol, encenderlas y 
arrojarlas al río. Los ingleses creyeron que se trataba del "fuego griego" y dieron orden de retirar las embarcaciones, aunque al dia siguiente volvieron al ataque. Este tampoco produjo ningún resultado y los ingleses se vieron obligados a abandonar el asedio sin haber logrado su objeto.

A pesar de algunas victorias obtenidas por los ingleses, tales como la toma de la Habana en América y la de Manila en Asia, se vieron obligados a aceptar la paz, la cual fue firmada en París el 10 de febrero de 1763. En él articulo 17 del tratado se convino en que "su majestad británica hará

Demoler todas las fortificaciones que sus vasallos puedan haber construido en la bahía de Honduras y otros lugares del territorio de España en aquella parte del mundo, cuatro meses después de la ratificación del presente tratado...."

\section{NELSON}

En los posteriores se produjeron diferencias entre los indios mosquitos y los zambos, y algunos de los jefes de los primeros celebraron tratados con las autoridades españolas. Así en 1777 se firmo un tratado por el gobernador de Cartago y en 1778 se firmaron otros por el gobernador de panamá y el teniente de gobernador de MATINA.

Los ingleses tomaron la ofensiva en centro América y lograron la captura del castillo de OMOA, aunque poco después fueron arrojados de allí por el capitán General de Guatemala don MATIAS de GÁLVEZ.

Los ingleses trataron entonces de penetrar por el San Juan, y esta vez no se trataba de una incursión pasajera sin proyecciones para el futuro. sino de un plan bien meditado para apoderarse de la ruta interoceánica por Nicaragua y que contaba con todo el apoyo del gobierno ingles. Al frente de esa expedición se puso al mayor J. POLSON. y como jefe de las fuerzas navales al entonces Capitán HORACIO NELSON quien después se cubrió de gloria, y encontró la muerte, comandando la escuadra inglesa en TREFALGAR. sobre esa expedición a Nicaragua NELSON escribió lo siguiente: "Yo intento poseer el lago de Nicaragua que al presente puede ser mirado como el GIBRALTAR terrestre de América Española."

El 11 de abril de 1780 los ingleses llegaron frente al castillo de la Inmaculada Concepción y lo sitiaron, hasta que el 29 del mismo mes el castellano JUAN de AYSSA hubo de rendirse por falta de agua.

A pesar de ese triunfo inicial la expedicion resultó un fracaso, pues la heroica resistencia del castillo dio tiempo a que el capitán general GÁLVEZ 
acumulara fuerzas considerables en la boca del rio San Juan en el lago de Nicaragua, y al poco tiempo el clima insalubre y la mala alimentación empezaron a hacer estragos entre los ingleses, obligando a los sobrevivientes a retirarse a San Juan del Norte en espera de refuerzos de Inglaterra.

Tomando entonces la ofensiva el capitán general GÁLVEZ, uno de los gobernantes más ilustres de Centro América, ataco a los ingleses en ROATAN y en rio TINTO. capturando y destruyendo todas sus fortificaciones.

\section{TRATADO DE VERSAILES}

En el tratado firmado en VERSAILLES entre España e Inglaterra el 3 de septiembre de 1783 , la segunda combino en el retiro de todos sus establecimientos en América Española, con excepción del de Belice pero como continuaran las argucias inglesas de que la costa MOSQUITA no era parte de América Española, se firmo un nuevo tratado en Londres el 14 de julio de 1780 y en él sé estipuló expresamente que todos los ingleses abandonarian esa costa y no suministrarian armas a los indios, y España por su parte se comprometió a no castigar a los indios por sus pasados crimenes.

Los ingleses cumplieron el tratado y abandonaron la costa MOSQUITA, y España estableció predios militares en río TINTO y CABO GRACIAS A DIOS. y por Real Cédula el 24 de sept. De 1786 se dispuso la fundación de ciudades en esos dos lugares y en BLUEFIELDS y la desembocadura del río San Juan.

Esos establecimientos se comenzaron por centroamericanos y en 1788 se enviaron 150 familias gallegas pero la insalubridad de los lugares y el abandono en que fueron dejados, hizo fracasar ese intento de colonización.

\section{LA REPUBLICA FEDERAL}

Después de la independencia y bajo la república federal de centro América. continuaron los avances ingleses en la costa de Mosquito y hasta hubo uno de ellos. el General SIR GREGOR MACGREGOR. que llego a proclamarse Cacique de POYAIS. El fundamento de este titulo se encuentra en una concesión otorgada en cabo gracias a dios por JORGE FEDERICO II, quien se titulaba rey de las costas y nación MOSQUITA.

Este mismo general MACGREGOR ofreció a España, ya consumada la independencia de C.A., la compra de las Isla de la bahia pero su propuesta no fue aceptada. Tanto la República Federal, como los estados que la 
componian estaban demasiado ocupados con sus discordias y no prestaban mayor atención alas usurpaciones inglesas, fuera de alguna que otra nota de propuesta.

\section{ChATFIELD}

El mismo año de la separación de Nicaragua se separo de C.A. el VICECÓNSUL ingles JOHN FOSTE protesto ante el gobierno de Nicaragua por la enajenación de tierras que decía eran de propiedad de los indios Mosquito, Nicaragua negó que la enajenación fuera cierta, pero proclamo su derecho a disponer sin ninguna interferencia de todos los terrenos dentro del territorio nacional.

Indudablemente la división de la república Federal de C.A. sirvió de estimulo ala ambición inglesa, provocando el deseo de aprovechar el debilitamiento causado por tal división.

Al mismo tiempo el gobierno de Nicaragua presentó protesta ante el cónsul ingles en Guatemala, MR. FREDERICK CHATFIELD, quien la contestó negando el derecho de Nicaragua y afirmando el de la monarquía MOSQUITA sobre el puerto de San Juan del Norte.

A principio de 1842 se presento nuevamente ante San Juan del Norte otro barco de guerra ingles pero se limito a intimidar al comandante y obligarlo a firmar un documento reconociendo la soberanía MOSQUITIA.

Afines de 1842, fallecieron Robert Charles Frederick, pretendido rey de los Mosquitios y en su testamento instituyó como regente y tutor de su heredero George Willians Clarence y de sus otros hijos, al coronel Mcdonald, y en su defecto a la persona que fuera nombrada por su majestad Británica, fortaleciendo así la influencia Inglesa sobre la costa de Mosquitos.

A fin de tratar de arreglar las cuestiones pendientes con Inglaterra, Nicaragua nombró Ministro en Londres y París al Lic. Francisco Castellón y secretario al Lic. Máximo Jerez. Ellos salieron en Marzo de 1844, y llevaban también la representación de Honduras para reclamar la desocupación de la Isla de Roatan que se encontraba en poder de los Ingleses desde 1841.

Antes de ser recibida esa delegación. fuerzas navales Inglesas ocuparon el puerto de Bluefields amediados de 1844, y Castellón protestó contra tal ocupación ante la Corte de Saint James. pero se le contestó que no sería escuchado, hasta que Centroamérica contara con una autoridad estable que

diera garantia, que fueran atendidos todos los reclamos pendientes de 
súbditos Británicos, por lo cual en Diciembre del mismo año de regreso para Nicaragua.

Al poco tiempo de haber regresado Castellón. Nicaragua nombró a José de Marcolete, uno de los diplomáticos más brillantes que ha contado su representante ante Inglaterra, Francia. Bélgica y Holanda. Marcolete tuvo bastantes dificultades para ser recibido y no fue sino hasta 1846 . que fue recibido por Bélgica y Holanda y un poco después que fue recibido por Francia.

El 10 de septiembre de 1847, el Cónsul Chatfield se dirigió a Sebastián Salinas, Ministro de relaciones Exteriores de Nicaragua, comunicándole que el reino Mosquito comprendía toda la costa Atlántica desde el Cabo Honduras, hasta el Río San Juan. sin perjuicio de los derechos que dicho Rey pudiera tener sobre cualquier territorio al sur de Río San Juan, y que el gobierno Ingles no vería con diferencia cualquier intento de usurpar los derechos territoriales del Rey de los Mosquitos, que está bajo la protección de la Corona Británica. A esto Salinas contestó negando la existencia del reino Mosquito y por lo tanto la existencia de cuestión territorial alguna entre él y Nicaragua , alegando que Inglaterra misma, al bloquear el puerto de San Juan del Norte en 1842, había reconocido la soberanía de Nicaragua sobre dicho puerto.

Con el fin de comprobar la actitud Hostil de los Indios Mosquitos era espontanea o inspirada por Inglaterra, el gobierno de Nicaragua envió comisionados a la Costa Atlántica y ellos se entrevistaron con la princesa Inés Ana Federica, hija mayor del difunto Rey Robert Charles Frederick. La princesa reconoció la soberania de Nicaragua . y el 28 de Octubre de 1847. fue firmada una convención en que se confirmaba esa soberania.

\section{OCUPACION DE SAN JUAN DEL NORTE}

El 26 de Octubre de 1847. se presentó en San Juan del Norte la fragata Inglesa "Alarm" portadora de un Ultimátum del rey de los Mosquitos a Nicaragua, pidiendo la desocupación del puerto antes del l de enero de 1848 .

El gobierno de Nicaragua envió a San Juan del Norte al General Trinidad Muñoz con una fuerza de 500 hombres para repeler la agresión. pero esa tropa permaneció en la desembocadura del Rio Sarapiqui en espera del resultado de platicas y arreglo.

Cumplidamente en la fecha señalada. el l de enero de 1848, llegó a San Juan del Norte el barco de guerra "Vixen" del cual desembarcó el Rey 
Mosquito protegido por 150 soldados Ingleses. Sin resistencia tomaron posesión del puerto. izaron la bandera Mosquita y nombraron autoridades.

Cuando las tropas Inglesas se reembarcaron el 9 de enero, el general Muñoz recuperó San Juan del Norte y restituyó en sus puesto a las autoridades Nicaragüenses.

Las fuerzas de Muñoz se encantonaron en seguida en la Isla de Trinidad, en la confluencia del sarapiqui y el San Juan, y alli fueron atacadas el 12 de febrero por tres barcos Ingleses, al mando de Granville Lock. quien se titulaba "Oficial Jefe de la División de Jamaica de la Estación de la India Oriental y América Septentrional, y Oficial Comandante de las Fuerzas Combinadas de S.M.B., en el Río San Juan de Nicaragua.

Cediendo ante las amenazas de terribles males para el país, los delegados Nicaragüenses consintieron en firmar el 7 de Marzo de 1848, el llamado tratado de la Isla de Cuba, en el cual se convino en la devolución de los prisioneros capturados por Nicaragua en la reconquista de San Juan del Norte lo mismo que de la Bandera Mosquita y otros artículos capturados; en que Nicaragua no perturbaria a los residentes de San Juan del Nortey que tal acto sería considerado por Inglaterra como una declaratoria de hostilidades; en que no se establecería aduana en la vecindad de San Juan del Norte; y en que Mr. Lock se retiraria devolviendo los prisioneros, rehenes y armas capturadas. En un articulo final ese tratado. Nicaragua se reservó al derecho de solicitar a su Majestad Británica el arreglo definitivo de la cuestión.

Poco después, Nicaragua envió plenos poderes a su encargado de Negocios en Londres don José de Marcoleta, para el arreglo de todas las cuestiones entre Nicaragua e Inglaterra , y envió además al Lic. Francisco Castellón en misión especial, pero ninguno de ellos pudo lograr el reconocimiento de los derechos de Nicaragua.

\section{TRATADO SELVA-HISE}

Mientras tanto. la prensa y la opinion Publica de los Estados Unidos protestaban con indignación contra los avances de Inglaterra en Nicaragua. pero el gobierno Americano procedia con cautela. En las instrucciones que el 3 de Junio de 1848, da el secretario de Estado James Buchanan a Mr. Elijah Hise, encargado de negocios en C.A: le hace notar que indudablemente la disolución de la confederación Centroamericana ha alentado a Inglaterra en sus pretensiones territoriales bajo el pretexto de protección al Rey de los Mosquitos. Que el probable propósito de la ocupación de San Juan del Norte es obtener el control de la ruta de un canal Interoceanico a través del lago de Nicaragua; y que aunque el gobierno Americano no ha resuelto aun el cambio 
a seguir en cuanto a las pretensiones Inglesas. Mr. Hise debe enviar toda la información posible sobre nuevos avances.

Mr. Hise parece haber sido un hombre de buenas intenciones aunque amigo de obrar por sus propias cuentas sin esperar intrusiones de sus superiores. El 20 de Dic. de 1848,Mr. Hise se dirigió al secretario de Estado señalando la conveniencia de que se le dieran poderes para ser tratados con todos los Estados de Centroamérica, y especialmente con Nicaragua para conseguir el derecho de paso por las comunicaciones terrestres o maritimas existentes o que en el futuro se estableciere; y el 12 de enero del año siguiente, sin haber recibido aun ninguna repuesta de Washington. se dirigió al Ministro de Relaciones Exteriores de Nicaragua pidiéndole enviar un comisionado a Guatemala para negociar un tratado de amistad y comercio. en el cual podrian ser insertadas estipulaciones sobre otros asuntos del mas profundo $\mathrm{y}$ alto interés para ambos piases y para el mundo en general.

Atendiendo la invitación de Mr. Hise, Nicaragua designó para negociar con el al Lir. Buenaventura Selva, que el 5 de junio de 1849. sometió la siguientes bases para un tratado:1) Nicaragua concedía privilegios exclusivos a favor de Estados Unidos o de sus nacionales, para la construcción del canal Interoceánico. Este privilegio tendría un plazo diez años, y si dentro de el se daba comienzo a los trabajos quedaria ampliado por 12 años mas; 2) Los Estados Unidos garantizaban la soberanía. Libertad e independencia de Nicaragua.

Mr. Hise aceptó en lo general las bases de Selva, y en ese mismo mes de Junio de 1849 se firmó el tratado SELVA-HISE, el primer tratado entre los Estados Unidos y Nicaragua.

Ese tratado fue desautorizado por los Estados Unidos, y las intrusiones que se dan al sucesor de Hise, Mr. George Squier, se le dicen que han sido inútiles todos los intentos de Nicaragua de que Bélgica mediara en su controversia con la Gran Bretaña, que el tratado de la Isla de Cuba deja la guerra a Nicaragua como único recurso y que sus pretendidos derechos del rey de los Mosquitos, no tienen ningún fundamento.

Además, en nota del 3 de mayo de 1849, el secretario de Estado Americano comunicó al Ministro de Relaciones Exteriores de Nicaragua que los Estados Unidos habian resuelto mediar en la controversia entre Nicaragua y la Gran Bretaña. Este ofrecimiento fue recibido con jubilo por Nicaragua aunque pasaría algún tiempo antes de que se lograra su resultado. 


\section{INTENTOS EN EL PACIFICO}

Por su parte, establecidos ya los ingleses en el extremo del Atlántico del proyectado canal interoceánico por medio de la ocupación de San Juan del norte por los Mosquitos trataron también de establecerse en el extremo de Pacifico, que por esa época se consideraba ser el golfo de Fonseca . para ello. el cónsul ingles CHATFIELD, quien recientemente había sido ascendido a encargado de negocios en Centro América , presiono con carácter de urgencia los reclamos ingleses contra Honduras, $y$ al no ser atendidos inmediatamente, se presento el 16 de octubre de1849 ante la Isla del Tigre con un barco de guerra, y la ocupación que la guarnición hondureña pudiera hacer resistencia.

Al conocerse tal ocupación por MR. SQUIER, este dirigió en nota del 23 del mismo mes a MR. CHATFIELD protestando contra ella como contraria al tratado entre los Estados Unidos y honduras celebrando el 28 de sep. del mismo año por lo cual se concedía a los Estados Unidos el derecho de ocupar esa Isla.

Ante tales provocaciones, y al pesar de que MR. SQUIER aconsejaba moderación ,Honduras el Salvador ,y Nicaragua comenzaron a reunir fuerzas y firmaron en León un tratado por el cual se unian los tres paises en un solo cuerpo , nacional que se llamaría representación nacional de Centro América y se instalaría en la ciudad de Chinandega. También se convienen que Guatemala y Costa Rica serian invitadas posteriormente a formar parte del pasado.

Mientras tanto Nicaragua proseguía sus gestiones diplomáticas en Londres aunque sin llegar a ningún resultado. En la entrevista que el 19de agosto de 1849 tuvo el encargado de negocios de Nicaragua, don JOSE de MARCOLETA, con LORD PALMERSTON , este le dijo que si Nicaragua hacia algún intento de recuperar San Juan del Norte . Inglaterra ocuparía El Realejo. Además le proponia la celebración de un tratado entre Nicaragua, Costa Rica y el Rey Mosquito, para convertir San Juan del Norte en un puerto libre. 


\section{ACTITUD AMERICANA}

\section{TRATADO CAYTON BULWER}

Mientras estos acontecimientos ocurrian en C.A.. los gobiernos de los Estados Unidos e Inglaterra reconocieron la importancia de 'solucionar por medios pacificos su constante lucha para obtener el control de la proyectada comunicación interoceánica, y el secretario de Estado John Clayton se dirigió al ministro Americano en Inglaterra, George Cancroft, y después a su sucesor, W.C. Rives, exponiendo el punto de vista de los Estados Unidos de que el canal no deberia quedar sujeto al control por un solo país, lo que ocurriria si Inglaterra conservara su protectorado sobre los Indios Mosquitos.

Las respuestas Inglesas eran definitivas en cuanto a la exclusión del monopolio sobre el control del canal, pero bastantes evasivas en cuanto al protectorado sobre los Mosquitos y habiéndose trasladado las negociaciones a Washington, el 19 de abril de 1850,fue firmado el tratado Clayton -Buwer, entre el secretario de Estado Clayton y el Ministro Ingles Sir Henry Lytton Bulwer. la mayor parte de las estipulaciones de este tratado refieren al proyectado de este canal interoceanico, excluyendo el control exclusivo sobre el mismo por parte de una sola potencia y conviniendo en su neutralidad, pero también contiene la prohibición tanto para Inglaterra como para los Estados Unidos, de ocupar, fortificar, colonizar, asumir ni ejercer ningún dominio sobre Nicaragua, Costa Rica ,la costa de los Mosquitos o cualquier parte de América Central, y de emplear o usar protección alguna ni alianza que ambos tengan o puedan tener con algún estado o Pueblo, con el propósito de construir o sostener tales fortificaciones, o de ocupar, fortificar o colonizar a Nicaragua, Costa Rica, la costa de los Mosquitos ni asumir o ejercer dominio sobre los mismos.( art. 1)

Inmediatamente después de la aprobación del tratado por el senado Americano y antes de su promulgación Bulwer presentó a Clayton una nota fechada el 29 de junio, declarando que el tratado no era aplicable a Honduras Británicas y sus dependencias. Esta nota fue contestada por Clayton el 4 de julio, aceptando que el tratado no era aplicable a Honduras Británicas" ni a las pequeñas islas en su vecindad que pueden ser conocidas como dependencias". 
Esta interpretación sirvió de pretexto al gobierno Ingles para proclamar, tan solo 14 dias después de la ratificacion del tratado, que las islas de roatan, Bonaca, Utila, Barbareto, Elena y Moraton en la costa de Honduras. formarian una colonia británica denominada Islas de la Bahía.

En cuanto a la costa de los Mosquitos en nota del 16 de agosto de 1850 . dirigida por Chatfield al ministro de relaciones Exteriores de Nicaragua, le dice que debe llegarse a un arreglo entre ambos paises en cuanto a la cuestión mosquita, pues el tratado Clayton- Bulwer, no solo no favorece las pretensiones de Nicaragua como esta supone. sino que por el contrario reconoce la existencia de la nación mosquita .

Además el 5 de dic. del mismo año volvió a dirigirse Chatfield declarando que la frontera entre Nicaragua y el reino Mosquito era la misma que existía el 15 de Septiembre de 1821 , y que corria desde la extremidad Norte de la línea que separa el distrito de Tegucigalpa en Honduras del de Nueva Segovia en Nicaragua, sigue la frontera Norte de Nueva Segovia. luego la frontera Este de Matagalpa y Chontales, y de ahí, en dirección este . llega hasta el Raudal de Machuca en el Río San Juan.

Asi se vieron frustradas las esperanzas que Nicaragua había cifrado en el tratado de Clayton - Bulwer para solución definitiva de la cuestión Mosquita, debiendo aun transcurrir bastantes años antes de que llegara a esa solución.

\section{PROPOSICIONES WEBSTER-CRAMPTON}

Posteriormente se celebraron negociaciones diplomáticas, tanto para la solución de la cuestión Mosquita , como para la fijación de limites entre Nicaragua y costa rica, cuestiones que encontraban intimamente ligadas por la relación que existia entre ambas y el proyecto canal interoceánico por Nicaragua.

En cuanto ala cuestión Mosquita , las proposiciones WEBSTER -CRAMPTON:

a) el territorio Mosquito se limitara así :de la desembocadura del río Rama en Atlántico se sigue hacia el oeste hasta llegar al meridiano 84.30 . de allí hacia el norte hasta llegar al río Coco y se sigue el curso de ese río hasta llegar nuevamente al Atlántico .

b) El gobierno de Nicaragua quedara obligado a respetar las concesiones de tierras fuera del territorio arriba delimitado ,que hayan sido hechas por el rey mosquito después del 1 de enero de 1848. 
c) Nicaragua pagara a los Mosquitos tres anualidades de los derechos que colecte en San Juan del norte al tipo del 10\% sobre el valor de las mercaderias importadas.

d) Los indios mosquitos podrán voluntariamente incorporarse a Nicaragua y en tal caso gozaran de iguales derechos y deberes que los otros Nicaragüenses.

Estas proposiciones fueron recibidas en Nicaragua con indignación y el $14 \mathrm{y}$ 16 de julio de 1852, las cámaras del congreso lo rechazaron, proponiendo someter la cuestión a arbitramento y protestando contra toda la intervención extranjera en los asuntos de Nicaragua y contra el uso de la fuerza para privarla de sus derechos.

\section{TRATADO DALLAS-CLARENDON}

Algunos años después los Estados Unidos y la Gran Bretaña hicieron un nuevo esfuerzo para arreglar amistosamente las cuestiones pendientes en C.A. y a ese efecto el 17 de Octubre de 1856. se firmó en Londres el tratado Dallas- Clarendon, entre George Dallas, ministro americano en Londres y Lord Clarendon, secretario de relaciones Exteriores Ingles.

En ese tratado ambos paises convinieron en proponer a Nicaragua la asignación a los indios Mosquitos de un territorio comprendido entre los ríos :Brachma y Rama, al norte y Sur respectivamente, y el océano Atlántico y el meridiano $84^{*} 15^{\prime \prime}$, al este y al oeste , respectivamente. Dentro de este territorio los indios mosquitos gozarian de autonomia, pero no podrían ceder su territorio a ningún otro estado, salvo que voluntariamente acordaran unirse a Nicaragua.

Además la gran Bretaña se obligaba celebrar un tratado con Guatemala para la demarcación de los limites a Belice tal como existía en la fecha del tratado Clayton-Bulwer, y otro con Honduras reconociendo a las Islas de la Bahía como un territorio libre bajo la soberania de esa república.

Inglaterra no aceptó esas reformas. con lo cual el tratado no entró en vigor y en vista que la controversia se hacia interminable. el presidente Buchanan declaró que el tratado Clayton-Bulwer invierte por completo la doctrina MONROE y la establece contra nosotros en vez de contra los gobiernos Europeos y llegó a proponer al congreso Americano la abrogación unilateral de tal tratado. 


\section{TRATADO ZELEDON-WYKE}

Las declaraciones del presidente Buchanan provocaron temor en Inglaterra. ya que el tratado Clayton-Bulwer era la garantia de que los Estados no tendrian control exclusivos del canal Interoceánico que llegaran a construir garantía que no fue abrogada sino por el tratado Hay -Pauncefote del 5 de febrero de 1900, y entonces el gobierno Ingles resolvió negociar independientemente con Guatemala. Honduras y Nicaragua y nombró como comisionado a Sir Willian Ouseley .

La misión de Ouseley en Nicaragua era la de firmar un tratado de amistad y comercio y otro en que Inglaterra renunciaba al protectorado sobre la mosquitia, pero solo el primero fue firmado el 18 de Enero de 1859(tratado Zeledon -Oușeley), y el 17 de febrero siguiente se le agregó un articulo que decía que tal tratado no prejuzgaba la cuestión Mosquita y que ella seria arreglada por una convención especial .

Esto no satisfizo a Inglaterra por dejar pendiente la cuestión mas importante y el tratado Zeledon-Ouseley fue rechazado, nombrándose como nuevo comisionado a Charles Lenox Wyke 'para negociar con Guatemala, Honduras y Nicaragua .

El 30 de Abril de 1859, Wyke firmó un tratado con Guatemala el 28 de Noviembre del mismo año, otro con Honduras y finalmente el 28 de enero de 1860, firmó con Nicaragua el llamado tratado de Managua o Zeledon-Wyke cuyas principales disposiciones son las siguientes :

1) Inglaterra reconoce como parte Integrante y bajo la soberanía de Nicaragua el territorio ocupado o reclamado por los mosquitos. El protectorado Ingles cesará tres meses después del canje de ratificaciones.

2) Nicaragua pagará a los Mosquitos cinco mil anuales durante diez años .

3) Cuando los mosquitos lo acuerden podrán incorporarse totalmente a Nicaragua y sujetarse a sus leyes.

4) San Juan del Norte será puerto Libre.

5) Las enajenaciones de terrenos hechas por los mosquitos con posterioridad al 1 de enero de 1848, y fuera del limite del territorio asignado, serán confirmadas siempre a) hayan bona fide y por justa compensación. B)No exceden de cien yardas cuadradas si es dentro de los limites de San Juan del Norte o de una legua cuadrada si es afuera de tales limites. c) no se opongan a otras enajenaciones anteriores hechas por España, Centroamérica o Nicaragua , necesite para fuertes arsenales $u$ otros edificios públicos. 


\section{LAUDO DEL EMPERADOR DE AUSTRIA}

Durante los hechos siguientes al tratado de Managua hubo varias dificultades entre Nicaragua e Inglaterra con respecto a la extensión del derecho de Autonomía que dicho tratado había concedido a los Indios Mosquitos, y sobre el derecho de Nicaragua a imponer impuestos a las mercaderias que pasaran por San Juan del Norte.

El 9 de Diciembre de 1878, Inglaterra propuso a Nicaragua que todas las cuestiones referentes a los Indios Mosquitos se sometiese al arbitraje del emperador de Austria, del Rey de Dinamarca o del de Suecia, y Nicaragua contesto aceptando el primero de ellos.

El Laudo Imperial fue dictado el 2 de Julio de 1881, y por el se decidió :

A) Que la soberania de Nicaragua sobre el territorio Mosquito estaba limitada por la autonomía concedida a estos.

B) Que Nicaragua tenia derecho de Izar su bandera en territorio Mosquito.

C) Que Nicaragua tenia derecho de mantener un comisario en ese territorio para garantizar sus derechos.

D) Que los Mosquitos podrian usar su propia bandera pero uniendo a esta un Emblema de la soberanía de Nicaragua.

E) Que el derecho de otorgar concesiones para explotar los productos naturales del territorio Mosquito no correspondia a Nicaragua sino de los Indios Mosquitos.

F) Que Nicaragua no tenia facultad de reglamentar el comercio de los Indios Mosquitos, ni a cobrar derechos sobre mercaderia importada al territorio reservado a estos o exportadas del mismo.

\section{RIGOBERTO CABEZAS}

El laudo arbitral del emperador de Austria no termino la cuestión porque los Indios Mosquitos pretendian ampliar mas aun su autonomia atribuyendo funciones en materia portales, monetaria. de cuarentena, de extradición y de entrada y salida de extranjeros y aun a imponer derecho de transito sobre las mercaderias que pasaran por su territorio para el interior de Nicaragua , todo esto ocasionó dificultades y protesta, llegando a tanto la osadía de los mosquitos que notificaron formalmente a Nicaragua. en ese entonces en guerra con Honduras que capturarian y desarmarian las tropas Nicaragüenses que cruzaran el territorio mosquito.

El fundamento Jurídico de la acción del general Cabezas fue expresado así por el ministro de Relaciones Exteriores de Nicaragua Dr. José Madriz, a los 
otros gobiernos de C.A: El decreto de 12 de febrero es puramente un negocio interno de soberanía íntimamente. El tratado de 1850, no liga ni puede ligar a Nicaragua a tolerar las faltas que cometa el gobierno municipal de la Reserva contra el poder soberano. $\mathrm{Ni}$ la represión de esas faltas puede considerarse como la ruptura del tratado ni como un hecho de que Nicaragua haya de responder ante la gran Bretaña.

Nicaragua debe acusar por tales faltas al jefe de la reserva ante el gobierno Británico, lo cual supondría algo mas que el protectorado; o ha de considerar a ese jefe como si fuese el de un Estado Extranjero sujeto al derecho de gentes, lo cual es contrario al tratado que declara a Nicaragua soberana del territorio y de la tribu de Mosquitos.

\section{ALTAMIRANO HARRISON}

Inglaterra protesto ante Nicaragua contra la ocupación de la Costa de los mosquitos pero no pudo hacer nada ante los hechos consumados.

Al año siguiente Inglaterra exigió a Nicaragua una indemnización de 15,500 libras esterlinas como compensación por los daños causados a algunos súbditos ingleses que fueron expulsados de la Mosquitia.

Siguieron después varios años de negociaciones infructuosas hasta que el 19 de abril de 1905, el Dr. Adolfo Altamirano ministro de relaciones exteriores de Nicaragua y Sir Herbert Harrison, encargado de Negocios de su Majestad Británica, llegaron a un acuerdo y suscribieron el tratado AltamiranoHarrison. En ese tratado se encuentran las estipulaciones siguientes:

a) Se abroga el tratado de Managua del 28 de enero de 1860 .

b) Se reconoce la absoluta soberania de Nicaragua sobre el territorio que formó la antigua reserva Mosquita.

c) Nicaragua propondrá a la asamblea nacional la emisión de una ley que excepciones por 50 años a contar del canje de ratificación, a los mosquitos y criollos nacidos antes de 1854, del servicio militar y de todo impuesto directo.

d) Nicaragua indemnizará concediéndoles terrenos baldios, a los indios cuyas tierras hayan sido adjudicadas a otras personas.

e) El ex jefe Mosquito Robert Henry Clarence podrá residir en Nicaragua sujetándose a sus leyes.

Nicaragua ha cumplido fielmente con todas las obligaciones que asumió en el tratado Altamirano Harrison en compensación por el reconocimiento por Inglaterra de su soberanía absoluta sobre todo su territorio; y el 24 de Agosto del año en curso es un a fecha gloriosa para el patriotismo de los Nicaragüenses ya que en ella llega a su vencimiento al única obligación que 
todavía quedaba vigente, o sea la excepción del servicio Militar y de los impuestos directos a favor de los indios Mosquitos y criollos nacidos antes de 1890. 